\title{
Digital video-based research in fashion: Visualising affect and sartorial vitality
}

This article examines the role of digital video in fashion research. It makes a case for the use of digital video as a valuable tool within the suite of research methods typically used in the field of fashion and dress. Its aim is to demonstrate digital video can enrich studies of fashion, specifically in its capacity to assist the capture and analysis of visual material unavailable to unmediated perception. Central to this is the technology's ability to document the dressed body in movement. The article discusses outcomes of a video based methodology with reference to participatory research activities termed 'sartorial sessions'. The approach used digital video technology to make possible the collection, analysis and manipulation of embodied material for close interpretation and analysis as well as for others to encounter. The article demonstrates the way digital media when used in conjunction with practiceoriented methods opens up new ways to understand and research the body in fashion. It concludes with reflection of how revelation of a background sartorial vitality opened up by digital technology can shift understanding of fashion from commodities or signs involved in the transmission of messages about wearers, or aesthetic propositions to powerful tools shaping our encounters in the world. 


\section{Introduction}

The propagation and circulation of moving images depicting the fashionable body have increased exponentially over the last decade. The growth of the internet and the associated participatory opportunities, along with the availability of digital devices used to consume, produce and share fashion related material have transformed the domain of fashion. Moreover, the capacity of digital media to capture and create affecting portrayals of the fashionable body in motion has led to the popularity of for-internet fashion film, which has become a ubiquitous feature of the contemporary fashion landscape.

It is perhaps not surprizing given the paradigmatic dimensions of this transformation the digital has been the subject of increasing scholarly interest in the field of fashion studies. Work on digital media and fashion (Rocamora, 2014, Rocamora, 2017), fashion film (Khan, 2012, Khan, 2013, Uhlihrova, 2013b, Uhlihrova, 2013a, Jobling, 2014, Khamis and Munt, 2010, Mijovic, 2013, Needham, 2013), fashion blogging (Rocamora, 2011, Findlay, 2017, Pedroni, 2015) and fashion and Instagram (Pedroni, 2016, dePerthuis and Findlay, 2019, Skjulstad, 2018) is representative of a growing body of scholarship that contends with this rapidly evolving digital media context. Despite the amount of academic activity devoted to this area there has been surprising little work undertaken to examine the use of digital video as a tool in fashion research. 
The aim of this article is twofold. Firstly, I wish to illustrate digital video when utilized with a combination of visual, material and corporeal based approaches available to researchers, offers significant potential to enrich studies of embodiment in fashion. I do this with discussion of a visual digital methodology aimed at exploring the interaction between bodies and garments that would escape notice in the vast majority of face to face encounters. Secondly, the article considers how examination of the movements of the dressed body made possible by digital video technologies opens up reflection upon the feelings and sensations of being-dressed. That is, the article considers those embodied, visceral and often ambiguous sensations that emerge from epidermal contact between the human body and garments that cover it as a mode of affectivity germane to sartorial experience.

Moreover, digital video provides means by which the body, its appearance and its movements, can be captured, documented and interpreted. One of the significant benefits of digital video is its capacity to explore the non-verbal or tacit aspects of a practice (Pink, 2007, Pink, 2009). This is made possible by the medium's capacity to show movements, gestures, performed skills, interactions with others, garments and material artefacts, all of which unfold in time. A significant advantage of using digital video for studies of fashion is that it can visualize aspects of bodily life that would normally not feature in a verbal or written account (Marchant, 2011).

This article illustrates the potential of digital video to uncover aspects of sartorial life, normally embedded within unfolding flows of action and as such do not feature in existing accounts of fashion and dress. With reference to an 
approach developed for the exploration of sensorial experiences in fashion (author , 2019) the article discusses the way in which digital video can open up a complex micro-corporeal background of behaviour by utilizing digital video's capacity to unlock what theorist Mark Hansen refers to as 'interstitial' moments in between images thus providing an observer a glimpse of the movements of the body imperceptible to unmediated perception (2004, p.587) .

The approach focuses upon the interactions of the body and the garment as they unfold in time. Digital technology can be a powerful tool which works in concert with both a corporeal focus and the use of design probes (Gaver et al., 1999, Boehner, 2012). Digital technology enables a particular way of capturing embodied data and a way of engaging with bodily movement as research material. Importantly digital media makes possible an exploration of the interstitial movements enacted by the body, that is 'background' movements and phenomena not available to conventional analysis. Hansen locates this perspective in proximity to critiques of technology within post-humanist discourses arguing digital media possesses an 'embodying' capacity where the body plays a central role as the 'selector' of images or the 'framer of information' in a digital context (Hansen, 2006, p.xxii). A concern with the micro-perceptual and background phenomena such as fleeting sensations, feelings and associated movements that transpire below a threshold of conscious awareness has been theorised in relation to 'affect'.

Theories of affect have had significant impact across the humanities and social sciences over the last two decades. Central to this has been the development of shared ontologies that acknowledge both 'natural and social phenomena are 
complex, processual, indeterminate, relational and constantly open to effects from contiguous processes' (Blackman and Venn, 2010, p. 8) . Accordingly, theories of affect have mobilized a vocabulary emphasising flows, forces and intensities that move between entities both living and non-living. Moreover, despite such theories not forming a homogenous body of theory they have offered novel ways to consider the body, often framed in terms of 'encounters', and the way in which bodies 'affect' and are 'affected'. As Patricia Clough writes affect refers to "bodily capacities to affect and be affected or the augmentation or diminution of a body's capacity to act, to engage , and to connect, such that auto-affection is linked to the self-feeling of being alive - that is aliveness or vitality' $(2007$, p.1) . Bodies in this sense are constantly being affected by and affecting other entities, forming and un-forming relations as a processual flow with the world around them. Bodies are not isolated containers, rather their relational nature is constantly drawing them beyond their 'surfaceboundedness , by their relation to, indeed its composition through, the forces of encounter [...] With affect, a body is as much outside itself as in itself--webbed in its relations' (Seigworth and Gregg, 2010, p.3).

While affect is theorised in relation to encounters and bodies, it also operates in the realm of digital media and technology. Contemporary visualities associated with imaging technologies of television, the internet and digital media make it possible to visualise affect but also for bodies to enter into affective relations through those technologies, shifting 'beyond bodies organic-physiological constraints' (Clough, 2007, p.2). Given these kinds of entanglements, theories of affect have assisted investigation of the way in which fashion images are produced the as well as how we encounter them. Notably Wissinger's work on 
fashion modelling investigated the way in which modelling professionals deploy forms of immaterial and affective labour (2007). The affective labour expended by models involves processes of channelling, modulating and amplifying affective flows present in the context of fashion shoots, in other words, being 'open to the flow' to self-produce shifts in 'demeanour, appearance, attitude' (Wissinger, 2007, p.264). According to Wissinger models work with these affective flows in person but also via virtually that takes place when others encounter fashion images. Shinkle (2013) similarly takes up theories of affect to consider the way in which the encounter with fashion images registers strong physiological effects on viewers that challenge ocular models of fashion spectatorship .

It is worth noting specifically upon how work on affect in fashion has focused upon the affective-technical link between image production and reception in the fashion system, while at the same time acknowledging theories of affect offer means to examine aspects of fashion tied to particular bodily and mental states that occur below a level of conscious awareness (Wissinger, 2007). Ruggerone has recently advocated an affective framework to examine the embodied interaction of garments and bodies, under the rubric of 'the feeling of being dressed' (2017, p.573). This work foregrounds being dressed as a 'mutual becoming of body and dress' while arguing an affective paradigm offers a framework to examine aspects of sartorial experience that are pre-reflective and 'extra-cognitive' (2017, p.578).

Given these methodological challenges in exploring what is in effect 'bodily, fleeting and immaterial' (Knudsen and Stage, 2015) I draw on a number of 
theorists to have examined the relationship between human corporeity and movement and the use of digital imaging technologies that work to visualise affect. The approach is indebted to the work of Massumi (2002), Hansen (2004) and Noland (2007, Noland, 2010) whom provide insight into the potential of digital media to excavate aspects of corporeal life unavailable to natural perception, while delineating a dimension of affectivity embedded in kinaesthetic movement (Stern, 2010). It is my contention in this article that digital video technologies offer studies of fashion an important tool to consider affective flows that pass through the dressed body. Despite the ephemeral nature of these affects, digital video's capacity to capture human bodies in movement and slow down images to examine sartorial movement in very close detail can provide a glimpse of the dynamic inter-relationships that revealed when observing the body in process (Featherstone, 2010) or in the field of fashion studies an 'dress/body assemblage' (Ruggerone, 2017, p.583).

It is important to emphasise this particular conception of affect distinguishes between more conscious affects experienced as categorial emotions; such as joy, anger or sadness (Noland, 2010) as well as more rational or deliberative cognitive processes associated with decision making and conscious thought and those inter- and intra-bodily states that transpire ' beneath , alongside or generally other than conscious knowing and emotional experiences' or otherwise 'vital forces insisting beyond emotions' (Seigworth and Gregg, 2010, p.1). Notably in this article I consider a kind of sartorial affect or vitality commensurate with a range of sensory and kinaesthetic sensations associated with the visceral experiences of being dressed. 
It is my contention there are affective bodily states and experiences germane to fashion and wearing clothing, that emerge when bodies are coupled with garments in co-creative assemblages of body and dress. In this regard the revelation of a background sartorial vitality opened up by digital technology can shift understanding of fashion from primarily commodities or signs involved in the transmission of messages about wearers, or aesthetic propositions to powerful tools shaping our encounters in the world.

In this article I demonstrate the potential of using digital video within fashion research to explore a kinesthetic and affective background underlying sartorial experience . I focus this primarily on the use of video in practice based work, a research approach currently increasing in visibility within fashion studies (Sampson, 2019) . I tease out the specific potentials embedded within the technology in relation to the work of artist Bill Viola, as well as pivotal practice-based example that exemplifies the technology's capacity to capture, document and assist examination of the dressed body in movement.

The video methodology reveals a range of self-directed actions, such as arranging and adjusting garments as well as specific bodily movements that have a sartorial basis thus opening up consideration of a sartorial reflexivity. In conclusion I discuss how digital video makes possible deeper reflection upon forms of affectivity germane to sartorial experiences and show how this has the potential to attune researchers to what are disregarded aspects of sartorial life. This raises a new set of concerns relevant to the study fashion and dress which add impetus to the questions of agency in fashion. : Are sartorial experiences 
positive or negative; and what kinds of opportunities for change, pleasure, enhancement, or sociality might sartorial practices engender ?

\section{Digital video in fashion research}

The study of fashion is inextricably bound to the images of the dressed body attested to by the 'reading' of the fashion image. Scholars have long relied on illustrations, paintings and photographs as sources of evidence to study fashion and dress (Hollander, 1993, Kawamura, 2011). Fashion studies as a field has also been strongly influenced by a semiological orientation which focus on the meaning and significance of the dressed body wherein images can serve as ideological mediums through which recognizable messages are conveyed (Shinkle, 2013).

Moreover, considering the historical and cultural significance of fashion and dress and its ubiquity in visual culture as well as the inherent dynamism of fashion, less attention has been devoted to researching fashion through the moving image. Fashion film itself appeared in the early 2000 s and was popularised by fashion photographer Nick Knight's and graphic designer Peter Saville's online portal SHOWStudio. The venture innovated the media form 
using the creative potential of digital media to exploit an " electronic logic" such as time , duration, movement, sound, and participation through interactivity and dialogue' (Uhlihrova, 2013a, p.139)

The emergence of digital fashion film has precipitated a reconsideration of fashion and its relationship to motion, often in terms of a dialogue between the traditional form of cinema and the contemporary manifestation of fashion film. Notable in this perspective is Uhlirova's work on fashion film situating the medium within a longer historical context, characterising its recent emergence in relation to " broader inter-medial practices and discourses in fashion, cinema, art and new media' while noting its 'emergence is inextricably bound to developments in digital media technology (2013, p. 138). While Khan (2013), (Khan, 2012)considers the emergence of fashion film in relation to emergent forms of mediality and designer creativity associated with digital technology and the internet.

While the significance of this area of study cannot be underestimated, such studies focus on fashion film as a novel digital media form in contrast to an opportunity to examine digital media's agentic role when used to study the interaction between garments and the body. The growth of practice based research in association with experimental and conceptual orientations has perhaps not surprisingly embraced digital video as a creative media. For example Bugg (2009) use of digital video as part of a generative practice based methodology showed the way digital media technologies are concomitant with new fashion practices that don't necessarily conform to the conventional models of commercial design. Similarly, fashion research practices oriented 
towards performative methodologies and exhibition contexts feature the use of video as a documentary tool to record choreographed performances of bodies and garments presented as creative installations. For example the exhibition Material, Memory and Media (2015) exemplifies this use of video, which according the exhibition's curator, 'illustrates that clothing designed as conceptual fashion and clothing designed as costume for performance now share approaches, which have developed through an increased awareness of the body and the agency of dress in communication.' In this context digital video offers a documentary capacity which aids the body to generate and communicate particular narratives that move beyond the 'traditional parameters of fashion and performance' (Bugg and Ziesche, 2016). Most promising in the area of digital video and fashion research is Marloes ten Bhömer recent work on bodily movement, gait and cinema in Walking women (2019) that brings together footwear design, scientific analysis and digital video to examine the way walking is reflective of particular gendered subjectivities.

Rather than seeking to enhance the communicative potential of the fashionable body set within particular narratives I consider digital video's capacity to excavate aspects of corporeal life normally unavailable to our natural perception. This critical orientation is located within a lineage of research on embodiment in fashion that calls for recognition of the sensuous, affective and experiential aspects of being dressed (Ruggerone, 2017, Entwistle, 2015, Negrin, 2016). These important contributions have argued for frameworks for embodiment research in fashion and serve as an important methodological scaffold for empirical work on the body and its relationship with clothing. 


\section{Why then Digital video?}

As Entwistle writes,' in everyday life dress is the insignia by which we are read, and come to read others (2015, p.35). In this sense the garments we wear form a visible envelope of the self in as much as we appear and act in the world and the world in turn responds to us as dressed. Yet it is also the case, the dressed body is not simply a visual motif but a fleshy being that actively participates in the world. Fashion as a designed object is conceived to be worn. Yet as Negrin has argued studies of fashion have failed to acknolwedge the experience of dresss as a 'tactile and embodied form, treating it primarily as a text to be decoded semiotically or as an image to be analysed in terms of its aesthetic form'. In this sense fashion is conceived as a 'specific look', while failing to recognise fashion is also about 'comporment of the body in space' (2016, p.115).

It is though a significant challenge to capture and interpret this dynamic interaction of body and garment. Wearing clothing comprises unfolding flows of human action; the vast majority of which don't carry legible meanings that we are conditioned to see and thus pass unnoticed within our face-to-face interactions. We are always in the midst of sartorial experiences, such as sensations of tactile contact, pressure and warmth as well as kinesthetic and proprioperceptive sensations as our body and garments are coupled in movement through space. However, these experiences take place at the level of the body and are largely invisible to an observer. Therefore, a investigation of the dynamics of the dressed body requires specific methods to produce sartorial action, but also specific technologies to capture, document and then interpret this embodied data. 
The rationale underlying the approach I developed was to visualize and examine the body in the midst of intense sartorial-sensory experiences. Given clothing produces direct tactile sensations upon the body, the use of a small range of purpose-designed garments were used in conjunction with sensory-tactile materials, including water, sand and beads ${ }^{1}$ to produce, amplify and visualise those sensations. Garments were designed to deliver tactile sensations through materials concealed in channels and pockets as well as deploying particular fabric properties.

There were two small ranges of garments produced. Garments themselves are understated as it was important their design did not signify or reveal the idiosyncratic functionality of the tactile provocations. The garment's shapes were developed from a combination of drape for the womenswear pieces and menswear coat with flat patternmaking and block modification. An intent motivating their design is to they appear as largely conventional fashion garments in accordance with contemporary aesthetics and functionality.

The garments were made from a linen fabric possessing a loosely woven structure which captured the fine granules of sand, while the choice of colour for different garments rendered the tactile materials either visible in the case of water (which transformed blue garments to a deep indigo colour ) to invisible in the case of beige coloured fabric when used with sand which foregrounded the movements of the body rather than their surface appearance. The premise 
for the use of these materials is their capacity to produce noticeable somatic effects in participants that registers in bodily movement.

Five participants were invited to participate in these sessions. Three women are involved in the first iteration, while two men in the second. The womenswear pieces integrated beads into channels and pockets in the garments as 'tactile provocations 'while the menswear ranges were used in conjunction with water and sand.

The participants are all drawn from informal creative and professional networks in academia and the arts. The individuals were invited to participate due to what appeared as a sensitivity to fashion and practices of self-styling. They were also selected on the basis of what I assumed was a deeper connection to fashion and clothing, which could enable them to be more comfortable as participants in a fashion research project. They ranged in ages from early twenties to late forties.

The sessions were largely unstructured, were often conversational and involved participants selecting and trying on different garments on, moving around, manipulating and exploring those garments. Sessions were designed as open and flexible contexts of exploration, to enable participants to interact and move around freely. A small digital camera was located in an unchanging position on a small tripod was used to document these sessions. The primary focus of these sessions was to create sufficient 'live complexity' in the form of movements, action and behaviour which could be digitally captured and subsequently examined, manipulated and reflectred upon. 


\section{A digital-corporeal frame}

A crucial advantage of digital video software is its flexibility to observe, study and manipulate moving images. This makes possible very close and repeated examination of visual material and in doing so particular aspects or sequences of movement emerge as significant. This process encompasses observation and identification of distinctive sequences of movement and the preservation of those sequences for further examination.

Visual material can also be reframed and cropped as well as discarding unwanted or uneventful sequences. This process of identification serves to distil visual material by identifying then, focussing on a repertoire of distinctive sartorial movements. Moreover, the capacity to select some sequences and remove others from visual documentation serves to foreground particular aspects that might normally go unnoticed. For example removing audio as well as de-identifying participants by reframing an image to remove the face to a position outside the frame serves to direct attention to the body with emphasis on distinctive movements and specific corporeal zones (and the concealment of others). Furthermore, the use of freeze frame and slow-motion function also enables an exploration of bodily movements in very close detail. The video methodology shifts emphasis from the face and speaking subjects to visceral focus upon bodies and movements.

The results of this digital-corporeal framing is echoed in Featherstone's discussion of the body in digital media as a 'movement-image' or 'body in process' (2010, p. 199) where what can be observed are very small movement of 
the body ' that cannot be perceived in the normal choreography of face-to-face interactions..' (2010, p.199). In this way digital imaging methodologies draws attention to what are difficult to visualise embodied sensations associated with movements and underlying vitality of the body and brings the focus onto the micro-corporeal movements and coordination of the body in relation to the garment.

\section{Vitality affects}

In The interpersonal world of the infant (1985) psychologist Daniel Stern characterizes the movements of neo-natal infants as indicative of a realm of dynamic sensibility or vitality. He associates 'vitality affects' with an infant's first experiences of movement with 'the body's sensations of itself as animate form', one that is constantly in movement and 'involves kinaesthetic distinctions, such as jerky versus smooth, taut versus relaxed which correspond to the infant's first experiences of movement' (Noland, 2007, p.19) .

According to Stern experiences of movement comprise an infant's entire existence and involve a range of pre-personal, pre-reflective sensations that transpire prior to the ascription of meanings through socialization. Babies learn to imitate facial responses of their mother and associate what are initially undifferentiated kinaesthetic experiences of muscular movements around the eyes, mouth and face. For example, the eyes are implicated in a smile which then render emotion and thus an intersubjective meaning (Meltzoff and Moore, 1977, Stern, 1985). 
Stern distinguishes vitality affects from categorical emotions such as anger, sadness and joy by pointing out sensations of movement precede the acquisition of emotions developmentally and thus underpin all mental and emotional experiences. While adults' sensitivity to kinaesthetic discriminations are somewhat desensitized, he argues they can be retrieved by using time based art forms such as music, dance and theatre (Stern, 2010). In other words, while these sensations are tied to a pre-reflective background of undifferentiated kinaesthetic sensation they can become available to us using different visual media and methods.

Commented [TR1]:

Carrie Noland takes up this issue of an undifferentiated kinaesthetic background with reference to Bill Viola's video and film works. Viola is an acclaimed video artist whom has developed a significant body of work focused upon corporeal representation and depictions of human emotion. Through a critical analysis of key examples of Viola's work Noland draws attention to variations in surface movements or 'tonicity' of the face and body of Viola's photographic subjects (Noland, 2007). 


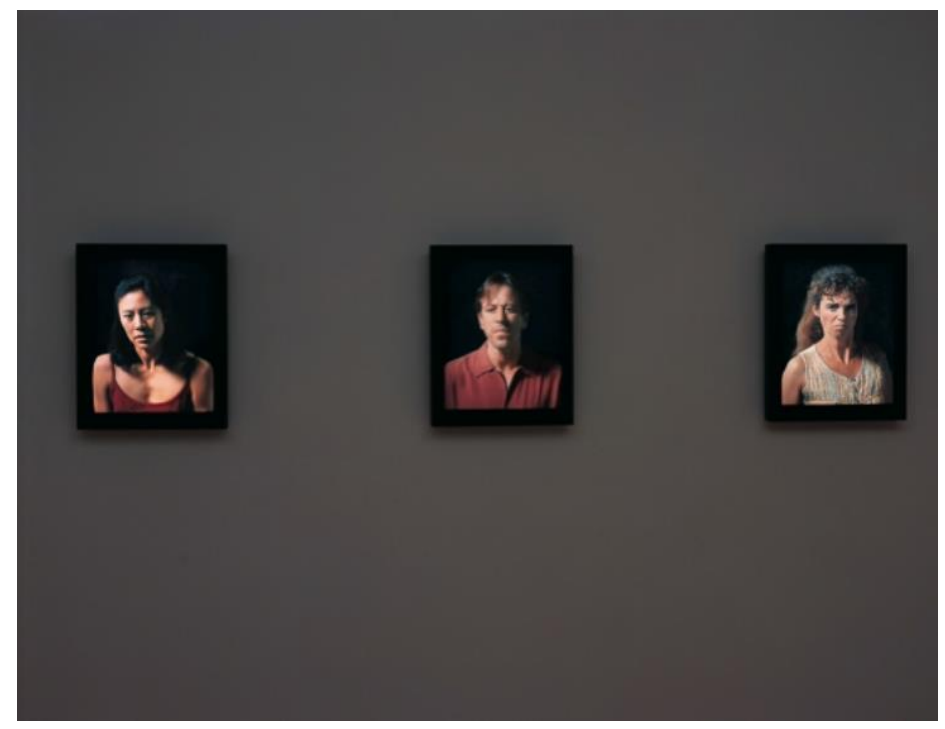

Figure 1 : Bill Viola, Anima (2000), , video triptych on 3 LCD flat panels mounted on wall

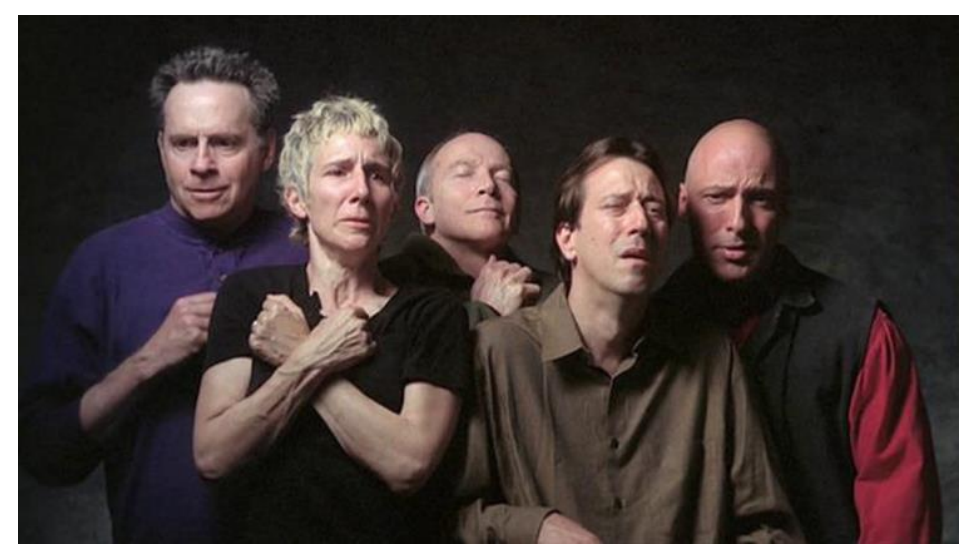


Figure 2: Bill Viola, The Quintet of the Astonished (2000), colour video rear projection on screen mounted on wall in dark room

One of the primary conceptual innovations of Viola's work has been depiction of people in the midst of intense physical and emotional experiences, shown at significantly decelerated speeds. His videos reveal movements of the human body imperceptible to unmediated perception. In works such as Anima (2000) and Quintet of the Astonished (2000) groups of people are documented expressing a variety of emotions. What is in fact witnessed is not the emotion expressed per se but rather the 'micro-stages' in between emotional states (Hansen, 2004,p.587). These are the imperceptible movements visible rippling through the skin and muscles observable on the surface of the body and the face. Noland characterizes these movements as 'projections' towards more resolved significations. She writes' However, these (as yet) non-taxonomized micro-gestures, these in-between phases through which the muscles pass, are nevertheless already directed toward, moving toward, the legible gestures between which they fall (2007, p.12).

\section{Excavating sartorial vitality}

While the work of Viola focuses on the human face as a site of identification, language and emotion, Noland's reframing of those in-between or interstitial movements of the body and face that underlie expressive emotion is in many ways analogous to smaller components of movement. Many of the movements 
enacted by the body would not be recognised in the vast majority of our face to face interactions as they reside within more extensive phases of practical action, that can be linked to particular projects or tasks. It is also the case the vast majority of our sartorial movements would not warrant consideration. For example, we might make a small movement of the hand to smooth or adjust a garment, or adopt a change in gait, posture or orientation, or any of the multitude of movements and actions human beings enact when dressed. Yet many of these corporeal variations would not be considered distinctive movements in themselves but rather smaller fragmentary components of larger sequences of movement. Thus, the development of this digital methodology implies a conceptual-creative approach that integrates conceptual work, designing garments and deploying those garments in situations to generate sartorial movement, so that it can be examined, explored and crucially shared with others. 

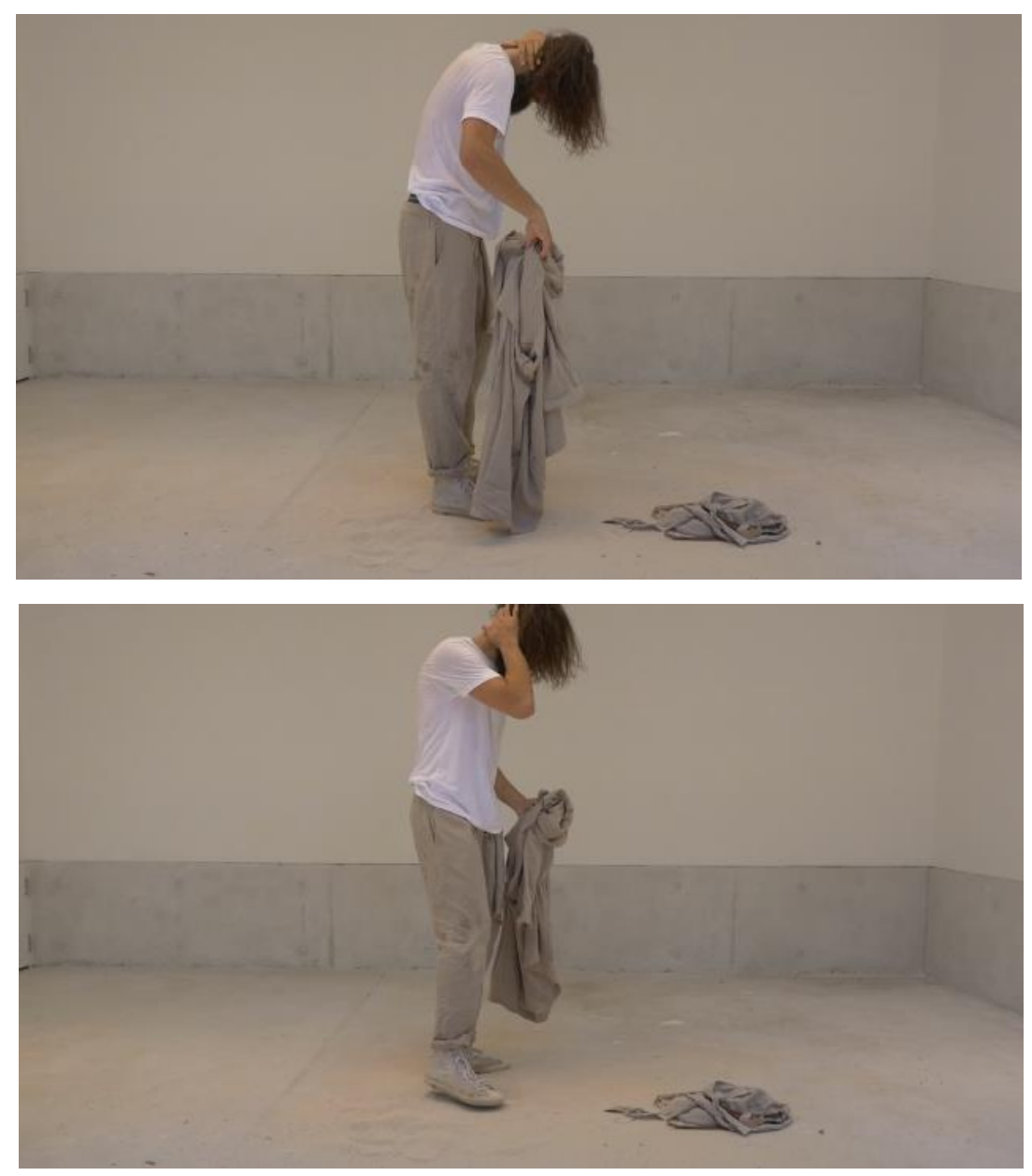

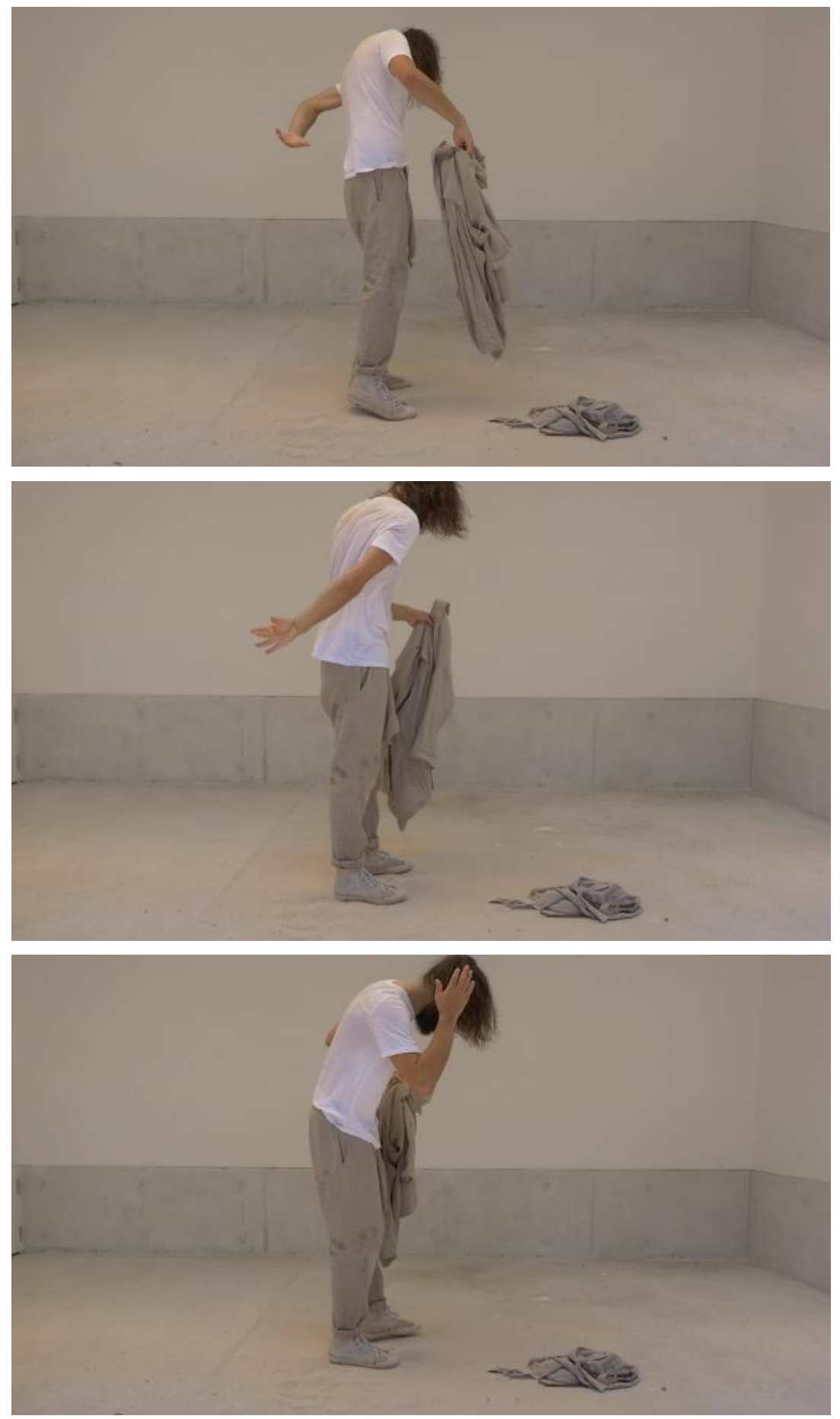

Figure 3: Author, Bruno (Sand) (2017), video still compilation 
For example, in Bruno (Sand) above the participant can be observed standing in the centre of the frame wearing a beige coloured outfit. In the video his body moves in response to sand trapped in his clothing. He rubs and shakes his arms and body, twisting and turning as he does so. His arms move rapidly, his feet pump up and down as he works to dislodge the sand . The sequences of movement are repeated, each time with improvised variations. Yet the movements which appear in the video as ongoing and an interlinked flow of movement were in fact discontinuous, emerging as more or less isolated actions and gestures in a much longer video sequence comprising raw documentary footage. In other words what were initially isolated movements - a rub here, a scratch there, a shake or twist of the body are integrated into a seamless whole through a digital process.

This involves a digital process whereby small sequences of movements are copied, manipulated, then reintegrated, in an iterative crafting process that involves an imbrication of the original sequence of movement with manipulated copies of itself, to create a continuous sequence of corporeal movement. Analogous to the excavation of micro-corporeal movements transpiring outside of conscious awareness in Viola's work discussed above, the methodology, via this digital process amplifies what are fleeting and ephemeral sartorial moments that might take a few seconds, to a much longer and significant sequence. In doing this what is normally mundane and unnoticed within the background of our awareness is transformed into a visible and significant thematic concern. 


\section{A kinaesthetic background and sartorial reflexivity}

What emerges in the above analysis is the consideration of how micromovements of the moving body can draw attention to a kinaesthetic and affective background. Noland describes the way in which this background is made up of the proprio-perceptive information or feedback the body is continuously in receipt of via its own movements (2007). This points to a way beyond analysing the movements of the body in terms of their semantic content, as we might analyse or interpret a gesture, but rather focuses on human beings' movements as rich in somatic associations. For example, when one is dressed, the movements enacted by the body do not only signify sartorial expressivity; they are also indicative of privately experienced somatic sensations. We can experience tactile sensations of garments against the skin, weight registering on different parts of the body, around the waist, the thighs etc.as well as the sensation of sartorial kinesis as we move through space and garments drape and shape around the body as we move. It is also the case these sensations, on reflection may be tinged with categorial affects, such as joy or pride, when we are feeling at our sartorial best; or excitement as we anticipate arrival at a fashionable event. Alternatively, we may experience shame, when we realise we have fallen out of fashion or a garment has grown too small, reveals signs of wear or dirt. It is also the case these experiences are diffuse, fleeting, and hard to articulate.

It is the case though these more conscious affects and the kinds of bodily sensations that precede them, do not work in predictable and uniform ways. 
Affects operate in feedback loops, where a "circus of affective responses' can manifest in a variety of ways from a single stimulus (Wissinger, 2007). For example, a fleeting sensation of fabric against the skin may register as form of body anxiety while at other times an enlivening sense of one's owns attractiveness.

While Bruno's movements detailed above originate in a background of undifferentiated kinaesthetic sensation, through the use of digital technology they can become available. In fact, the methodology amplifies a background of sartorial vitality into a visible thematic concern so others can observe and consider these sequences of movement as well. In other words, while a background vitality is concealed beneath our more conscious thoughts and activities it remains accessible. As a number of thinkers of the body have argued (Leder, 1990, Csordas, 1993, Stern, 2010, Shusterman, 2008) there are important political and ethical implications associated with our capacity for somatic reflexivity. Stern argues such sensitivity is essential for intersubjective bonds underpinning 'empathy, sympathy and identification." (Stern, 2010). Noland explains while sensitivity to embodied sensation enables participation in 'bodily practices across culture' they also make possible 'variations in performances' of those bodily practices. Within these variations she argues lies a potential source of cultural and social change whereby:

These variations can accumulate and cascade into forms of innovation, and yes, resistance that produce profound effects on behaviour, effects that spread out, into the realm of conscious decision making, and other more mindful areas of cultural and political practice (2010, p. 3). 
In this sense reflection upon one's sartorial vitality is neither solipsistic nor apolitical, but rather a potential source of political and cultural action. As studies of power dressing showed there are political as well as economic consequences to the way in which dress is worn, experienced and interpreted (Entwistle, 1997). It is also the case that while forms of bodily movement are shaped by historical and social forces that act upon the body, it is also the case a kinaesthetic agency and potential underpins those movements.

In perspectives that conceptualise the dressed body as a dynamic entity the issue of agency and bodily comportment will inevitably arise. That is the extent to which what we wear and how we wear it impinge upon our capacity to act in the world. As such investigation of the way fashion confers an aliveness upon its participants offers valuable perspectives to understand the dynamics of fashion. This perspective contrasts with the historically dominant ways in which fashion has been subjected to semiotic analysis which foreground static bodies and deny wearers much in the way of agency. The salient point here is how sensitivity one's own as well as other's ways of moving ( and dressing) means opportunities may arise to harness variations in sartorial movement in order to develop new ways of bodily comportment.

\section{Conclusion}

While fashion's digital transformation continues unabated there remains significant opportunities to integrate these technologies and their insights into how the body can be examined in the field of fashion studies. As I have 
demonstrated a digital approach thus offers an important tool within

interdisciplinary empirical work on the body in fashion as well as providing a means to engage productive dialogues with emerging perspectives on the body, fashion, embodiment and affect. The digital methodology serves the generation and capture of embodied data that can be subject to iterative exploration and analysis in order that aspects of sartorial life that resist conventional analysis can be articulated and represented, so others can engage with these findings. It is also the case that while digital technology is a novel research tool in the context of fashion, its use raises the question of a 'politics of method', that is, what kind of knowledge about fashion and dress do we wish to mobilise ? (Lury and Wakeford, 2012). As I have suggested the revelation of sartorial vitality points to not only what it feels like to be dressed but also how enhancements of sartorial self-reflexivity may in fact enhance our power to act on the world.

Bibliography

BLAekMAN, L. \& VENM, C. 2010. Affect, Body \& Society, 16, 7-28

BOEHNER, K., WILLIAM GAVER, AND ANDY BOUGHER. "I4 " (2012): 185. 2012. Probes. Inventive Methods: the Happening of the Social Abingdon: Routeledge.

BUGG, J. 2009. Fashion at the Interface: Designer-Wearer-Viewer, Fashion Practice, 1, 9-32.

BUGG, J. \& ZIESEHE, A. N. 2016. Mediated materiality and meaning, curating experience through the body and dress, Genève, Head publishers.

CLOUGH, P. 2007. Introduetion. In: KIM, H. \& BIANCO, J. (eds.) The affective turn: Theorizing the social, Durham M.G.: Duke University Press.

ESORDAS, T. 1993. Somatic Modes of Attention. Gultural Anthropology, 8, 135 . 156. 
DEPERTHUIS, K. \& FINDLAY, R. 2019. How Fashion Travels: The Fashionable Ideal in the Age of Instagram. Fashion Theory: The Journal of Dress, Body \& Eulture, 1-24.

ENTWISTLE, J. 1997. Power Dressing and Fashioning of the Gareer Woman. In: M. MAVA, I. Mo, A. BLACK, AND B. RICHARDS (ed.) Buy this Book: Studies in Advertisitng and Consumption. London: Routledge.

ENTWISTLE, J. 2015. The Fashioned Body; Fashion, Dress and Modern Social Theory, Gambridge, UK \& Malden, USA, Polity.

FEATHERSTONE, M. 2010. Body, image and affeet in consumer eulture. Body \& Society, 16, 193-221.

FINDLAY, R. 2017. Personal Style Blogs: Appearances that Fascinate, Bristol, UK., Intellect.

GAYER, B., DUNNE, A, \& PASeENTl, E. 1999. Design: Cultural Probes. Interactions, 6, 21-29.

HANSEN, M. 2004. The time of affect, or bearing witness to life. Gritical Inquiry, 30, 584-626.

HANSEN, M. 2006. New Philosophy for New Media, Cambrige, Massachussets, MIT Press.

HOLLANDER, A. 1993. Seeing Through Glothes, Berkeley, University of California Press.

JOBLING, P. 2014. Border erossings: fashion in film/fashion and film. In: BLACK,

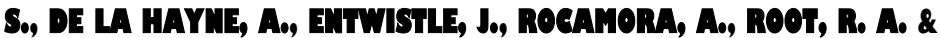
THONAS, H. (eds.) The Handbook of Fashion Studies, London: Bloomsbury Academic.

KAWAMURA, Y. 2011 . Doing researeh in fashion and dress : an introduction to qualitative methods, Oxford, Berg.

KHAMIS, S. \& MUNT, A, 2010. The Three es of Fashion Media Today:

Convergence, Greativity \& Control. Scan Journal of Media Arts Gulture, 8.

KHAN, N. 201 2. Cutting the Fashion Body: Why the Fashion Image Is No Longer Still. Fashion Theory: the Journal of Dress, Body \& Culture 16, 235-250.

KHAN, N. 2013. Stealing the moment: The non-narrative fashion films of Ruth Hogben and Gareth Pugh. Film, Fashion \& Consumption 1, 251-262.

KNUDSEN, B. T. \& STAGE, C. 2015. Introduction. Affective methodologies : developing cultural researeh strategies for the study of affect. Basingstoke: Palgrave Maemillan.

LEDER, D. 1990. The Absent Body, Chicago, University of Chicago Press.

LURY, G. \& WAKEFORD, $\mathrm{H}_{0}$ (eds.) 2012. Inventive methods: The happening of the social: Routledge.

MARGHANT, S. 2011. The Body and the Senses: Visual Methods, Videography and the Submarine Sensorium. Body \& Society, 17, $53-72$

MASSUMI, B. 2002. Parables for the Virtual: Movement, Affect, Sensation, Durhanm\&London, Duke University Press.

MELTZOFF, A. N. \& MOORE, M. K. 1971. Imitation of facial and manual gestures by human neonates. Seience, 198, $75-18$.

MIJOVIC, N. 2013. Narrative form and the rhetoric of fashion in the promotional fashion film. Film, Fashion \& Consumption, 2. 
MEEDHAM, G. 2013. The Digital Fashion Film. In: GIBSON, S. B. A. P. G. (ed.) Fashion Cultures Revisited: Theories, Explorations and Amalysis. Abington: Routledge.

MEerin, L. 2016. Maurice Merleau-Ponty: The Corporeal Experience of Fashion. In: ROCAMORA, A. \& SMELIK, A. (eds.) Thinking Through Fashion: A guide to the key theorists, London, New York: I.B. Taurus.

NOLAND, C. 2007. Motor Intentionality: Gestural Meaning in Bill Viola and Merleau-Ponty. Post Modern Gulture.

MOLAND, C. 2010. Agency and Embodiment: Performing gestures/producing eulture, Harvard University Press.

PEDRONI, M. 2015. Stumbling on the heels of my blog": Career, forms of capital, and strategies in the (sub) field of fashion blogging. Fashion Theory: The Journal of Dress, Body \& Culture, 19, 179-199.

PEDRONI, M. 2016. Meso-celebrities, fashion and the media: How digital influencers struggle for visibility. Film, fashion \& consumption 5, 103 121.

PINK, S. 2007. Walking with Video, Visual Studies, 22, 240-252

PINK, S. 2009. Doing sensory ethnography, London, Sage.

Rocamora, A. 201 I. Personal Fashion Blogs: Sereens and Mirrors in Digital Self-portraits. Fashion Theory: The Journal of Dress, Body \& Culture, 15.

ROGAMORA, A. 2014. New Fashion Times: Fashion and Digital Media. In: BLACK, S., DE LA HAYNE, A., ENTWISTLE, Jo, ROGAMORA, A., ROOT, R. A. \& THOMAS, Ho (eds.) The Handbook of Fashion Studies, London: Bloomsbury Aeademic.

ROCAMORA, A. 2017. Mediatization and digital media in the field of fashion. Fashion Theory: The Journal of Dress, Body \& Culture, 21 , 505-522.

RUGGERONE, L. 2017. The Feeling of Being Dressed: Affeet Studies and the Clothed Body. Fashion theory: The Journal of Dress, Body \& Culture, 21 , 573-593.

SAMPSON, E. 2019. The Gleaved Garment: The Maker, The Wearer and the "Me and Mot Me" of Fashion Practice. Fashion Theory: The Journal of Dress, Body \& Gulture, 22.

SEIGWORTH, G. \& GREGG, M. 2010. An Inventory of Shimmers. The Affect Theory Reader, Durham, Ne Duke University Press.

SHINKLE, E. 201 3. Uneasy bodies: affeet, embodied perception and contemporary fashion photography. In: ZARZYCKA, M. \& PAPENBURG, B. (eds.) Carnal aesthetics: transgressive imagery and feminist politics. London: IB Tauris.

SHUSTERMAN, R. 2008. Body conseiousness: a philosophy of mindfulness and somaestheties, Gambridge, Cambridge University Press.

SKJULSTAD, S. 2018. Vetements, Memes, and Conneetivity: Fashion Media in the Era of Instagram. Fashion Theory: The Journal of Dress, Body \& Culture [Online]. [Aceessed I Oetober].

STERN, D. 2010. Forms of Vitality, Oxford, Oxford University Press. 
STERM, D. N. 1985. The Interpersonal world of the Infant: A view From Psychanalysis and Developmental Psychology, New York, Basic.

UHLIHROVA, M. 2013a. 100 Years of the Fashion Film: Frameworks and Histories. The Journal of Dress, Body \& Gulture, 17, 137-158.

UHLIHROVA, M. 2013b. The Fashion Film Effect. Fashion media : past and present, London: Bloomsbury Academic

WISSINGER, E. 2007. Modelling a way of life: Immaterial and affective labour in the fashion modelling industry. . Ephemera: Theory and Polities in Organization, 1 250-269. 